\title{
AN ONLINE RESOURCE HUb FOR ENGINEERING FACULTY: Providing Practical INFORMATION AND SUPPORT FOR OUTCOMES-BASED EDUCATION
}

\author{
A. M. Parker, N. Dyck, J. P. Carey \\ Faculty of Engineering, University of Alberta, Edmonton, Alberta \\ aparker@ualberta.ca,jpcarey@ualberta.ca
}

\begin{abstract}
Faculty resistance toward outcomesbased education $(O B E)$ can be sorted into two categorieslack of understanding and lack of resources - and can be addressed by leadership through increased education and communication.

With this in mind, the Faculty of Engineering at the University of Alberta has created an online OBE Resource $\mathrm{Hub}$ on its faculty intranet, guided by the question, "What kinds of education and communication do faculty require to gain knowledge and acceptance of $O B E$, and therefore be engaged and motivated in the process?"

Artifacts on the ever-growing site include theoretical and practical information in the form of articles, tipsheets, videos, and external links. This article showcases the site, since an initiative of this nature might be of interest to other post-secondary faculties working toward OBE.
\end{abstract}

Keywords: Outcomes based education, graduate attributes, faculty resistance, faculty support.

\section{INTRODUCTION}

In faculties of Engineering across Canada, outcomesbased education (OBE) takes the form of twelve graduate attributes integrated into the curriculum, with resulting student assessment data being used to inform continual program improvement [6]. The shift from inputs (what is taught) to outcomes (what is learned) has been in response to the nature of engineering work crossing geographical borders, necessitating uniform standards for professional skills, such as communication, teamwork, problem solving, and lifelong learning [15].

Despite this change in engineering education beginning two decades ago and now approaching global compliance, faculty resistance to OBE persists [15]. Concerns and issues raised are varied and entangled, primarily relating to OBE being an external mandate imposed upon faculty, thus threatening academic freedom, and its potentially negative impacts on teaching and learning [15].

At the institutional level, OBE and data-informed program improvement is becoming recognized as imperative for higher education globally, engineering or otherwise, and buy-in is necessary for an institution to remain relevant and appealing in a rapidly changing world $[16$, p. 31]. At the engineering classroom level, OBE is a step in the effort toward teaching excellence, a point where instructors are reflective and able to develop learning activities that help students achieve the expected outcomes [12].

According to Bresciani (2006), strategies employed by leadership aimed at mitigating faculty resistance must address both education and communication [5]. With this in mind, the Faculty of Engineering at the University of Alberta has created an online OBE Resource Hub on its faculty intranet, which, at present, is in a pilot phase with its intended users. Artifacts include theoretical and practical information in the form of articles, tipsheets, videos, external links, and more. Construction of the site continues to be guided by the question, "What kinds of education and communication do faculty require to gain knowledge and acceptance of $\mathrm{OBE}$, and therefore be engaged and motivated in the process?" The purpose of this paper is to showcase the site in its draft form as an effort toward mitigating faculty resistance to OBE. Results from an informal survey conducted with a small group of intended users are presented to supplement our explanation of the site's layout and content.

\subsection{Literature Review}

OBE in engineering has its roots in mutual recognition agreements between countries such as the Washington Accord, with Canada being among the first signatories in 1989 [15]. The Canadian Engineering Accreditation Board $(\mathrm{CEAB})$ introduced OBE into its accreditation criteria in 2009, whereby institutions must demonstrate that graduates of a program possess twelve specified attributes, and that data from assessment of these attributes is being used to inform continuous program improvement [6].

Discussion of faculty resistance to OBE is prevalent in the literature, in some cases relating specifically to engineering, while at other times taking an institution-wide perspective to include other disciplines adopting this 
relatively new paradigm. Concerns point to the potential impacts on faculty (such as increased workload and loss of academic freedom), on students (which can also impact faculty in the form of unfavorable teaching evaluations), as well as the feasibility of the pedagogical approach itself.

1.1.1. Increased Workload. Limited time for the increased workload of OBE implementation is one of the barriers most typically reported [5, p. 119]. The collection and analysis of graduate attribute assessment data, as well as the ongoing redevelopment of curricula, is regarded as an externally motivated and bureaucratic process that imposes additional responsibilities on faculty, who are already busy with research, teaching, and administration priorities $[2,15]$.

1.1.2. Loss of Academic Freedom. A culture of autonomy exists at academic institutions. This arguably has a positive impact on the student experience, and outcomes that are too prescriptive can thwart curricular innovation $[3,11]$. OBE implementation imposes an attitudinal shift on this sense of academic freedom. It requires that an undergraduate program be reframed as not a series of disjointed courses taught by instructors who are highly specialized in their areas of research, but rather as an integrated experience where student learning and attainment of graduate attributes is scaffolded over several years [11].

1.1.3. Unfavorable Teaching Evaluations. The nature of graduate attributes does not align with the traditional education model, which is the transmission of factual content from teacher to student [11]. Instead, a nondidactic, student-centred approach is required [14]. This may not satisfy student expectations of being passive recipients of information, resulting in poor teaching evaluations and possibly impacting employment status or yearly merit awards for faculty members [1, 5 (p. 122)].

1.1.4. Feasibility. Clanchy and Ballard (1995) explained that individuals cannot truly possess graduate attributes, but rather can only demonstrate them in certain contexts. With this, they questioned if universities should be held responsible for the attributes (and therefore values and behaviours) of students. For example, a student may display an understanding of ethics for a particular classroom project, yet then move on to behave unethically in the field [8]. Engineering-specific concerns in the literature also question the intention and practicality of the CEAB mandate, taking issue with certain graduate attributes, including the Design and Investigation attributes [15].

Bresciani (2006) sorts reasons for faculty resistance toward OBE into two categories - lack of understanding and lack of resources [5]. Lack of understanding includes concerns around the unfamiliar conceptual framework, terminology, and pedagogical value of OBE, as well the value of one's active participation. This can materialize into skepticism and fear around the potential loss of academic freedom or other significant divergence from the status quo. Lack of resources, on the other hand, includes concerns regarding finding time for the imposed additional workload, as well as support, perhaps in the form of professional development, funding, software, theoretical and practical information, document templates, and more. Leadership can address the barrier of faculty resistance due to lack of understanding and resources with a two-pronged approach — with ongoing education and communication [5]. Faculty involvement, rather than an entirely top-down approach, can increase feelings of understanding and ownership and lead to greater faculty engagement and motivation [2, 16 (p. 198), 17].

Maintaining good standing with an accrediting body and all other stakeholders may be the impetus for OBE implementation; however, it can be helpful to reframe it instead as being a catalyst toward teaching innovation and excellence [4, 12 (p. 224), 16 (p. 18)]. Foundationally, outcomes are intentions and evidence for student learning, and, within this structure, instructors do have the freedom to select content and methods toward achieving the outcomes [11]. Guiding the student experience by specifying what we want students to learn, how we are going to help them learn, and then determining if learning has occurred, is simply good pedagogical practice [11]. OBE is a current and ongoing paradigm of engineering education globally [11]. In addition to accountability to all stakeholders, responsiveness to the needs of students is the benchmark of a quality institution [4, 12 (p. 224)]

\section{METHODOLOGY}

Development of the online OBE Resource Hub within the University of Alberta's Faculty of Engineering intranet is rooted in Bresciani's (2006) assertion that education and communication are key to addressing faculty resistance to OBE [5]. It is also guided by a thorough literature review that summarizes the extensive OBE discussion in the annual Canadian Engineering Education Association (CEEA) conference proceedings over the 2010 to 2017 timeframe [15]. Themes and terminology drawn from this paper serve to provide the Resource Hub's organization of artifacts within topic and subtopic headings.

The idea and subsequent growth of the Resource Hub to its present draft form was derived by the authors of this paper-Associate Dean (Programs \& Planning), Director (Programs \& Planning), and Research Associate for Engineering Pedagogy - in the spring of 2019. It was envisioned to be a means for transforming the known theoretical rationale and best practices of $\mathrm{OBE}$ in engineering education into a portal to practical information and support for faculty.

The site currently resides on eClass, the University's learning management system (Moodle). This platform is both familiar and robust, and therefore well-suited to the 
resource. Construction and curation of the artifacts so far has been an iterative process.

In late 2019, initial feedback was sought from key Engineering faculty members and pedagogy experts from the University's Centre for Teaching and Learning. The survey provided background information about the site, asked twelve Likert-style questions relating to its layout and content, and invited respondents to elaborate with longer text answers.

\section{FINDINGS}

One Engineering faculty member and two pedagogy experts from the University's Centre for Teaching and Learning reviewed the OBE Resource Hub and completed the survey that was administered in late 2019. All respondents were forthright in their evaluation and generous with suggestions for improvement and ideas for new artifacts.

\subsection{Site Layout}

The layout quality of the site was rated as good overall. Respondents said that navigation was facilitated by the use of a collapsible topics format and logical headings and subheadings.
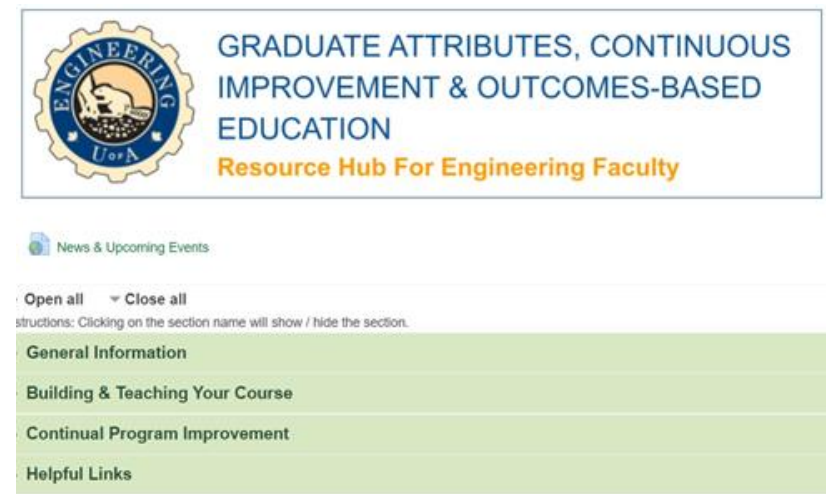

Fig. 1. Layout of the OBE Resource Hub site, topics collapsed.

View-only Google documents were seen as a suitable choice for text-based articles. Some recommendations for improvement were as follows:

- Use a table of contents or FAQ section as an entry point into the site, helping users know what to expect from each artifact

- Provide brief descriptions alongside each subheading

- Enlarge, underline, and bold the headings for enhanced readability

- Choose text and highlighting colours better suited for on-screen reading

\subsection{Site Content}

Respondents rated the content quality of seven artifacts as good overall, which included a short video, an annotated bibliography, several articles, and a database of authentic assessment examples.

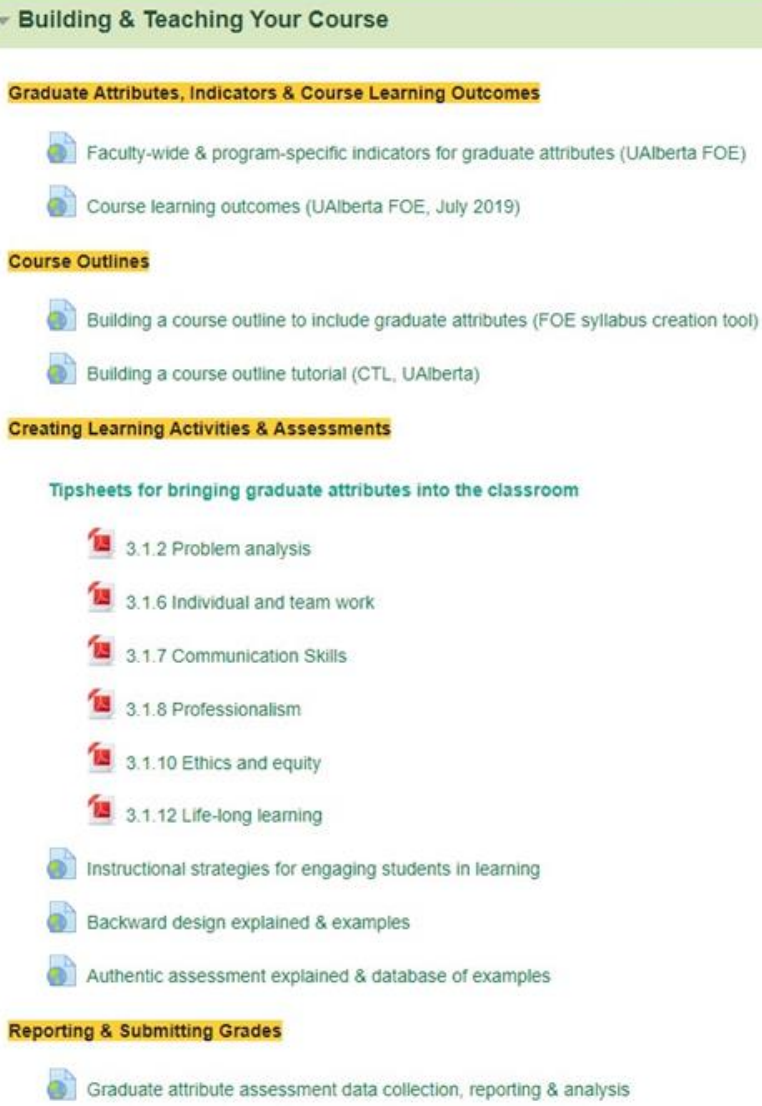

Fig. 2. Content of the Building \& Teaching Your Course topic of the OBE Resource Hub.

Improvement suggestions and ideas for more resources were as follows:

- Simplify language for readers who may be less versed in pedagogy

- Shorten documents to one page and use colour and graphics for interest

- Use colour coding to match course learning outcomes to graduate attributes

- Create an attractive poster that captures key aspects of OBE

- Create a one-page guide for writing learning outcomes

- Create a succinct resource summarizing graduate attribute reporting requirements by instructors 


\section{DISCUSSION}

Results from the survey conducted in late 2019 confirmed that the OBE Resource Hub is en route to its intended function of being a portal to practical information and support for Engineering faculty, increasing their knowledge and acceptance of OBE, as well as their engagement and motivation in the process. Constructive feedback from survey respondents pertained mostly to ways for making the site easier to navigate and each artifact more concise, thus resulting in users being able to find the right information quickly.

Several feedback items have already been incorporated into the site. For example, we have created a series of printable one-page tip sheets that provide classroom-ready activities and assessments for many of the CEAB graduate attributes, specifically 3.1.2 Problem analysis, 3.1.6 Individual and team work, 3.1.7 Communication skills, 3.1.8 Professionalism, 3.1.10 Ethics and equity, and 3.1.12 Lifelong learning [6].

Due to the dynamic nature of the engineering classroom and industry, it is unlikely that the OBE Resource Hub will ever reach a point of completion; however, now having the framework in place reduces the inertia of such a resource being developed from scratch. It is anticipated that the existing site will be a significant first step toward reducing faculty resistance to OBE and increasing the likelihood that graduate attributes will be integrated into the fabric of classroom activities and assessments.

The survey conducted in late 2019 served to refine the draft site and prepare for its launch to the general Engineering faculty. Beyond this, the OBE Resource Hub's content and overall reason-for-being has the potential to be the centre of more meaningful research. For example, the initiative could drive a practical action research study by a team of faculty members. Instead of the site being for instructors, it can be developed by instructors to build a community of practice - to increase knowledge and acceptance of OBE and to change teaching materials and methods accordingly. This initiative is fitting for action research, because it centres around a specific educational problem (faculty resistance to OBE) and an attempted solution toward improving practice [9 (p. 579-584)].

Within a practical action research framework, the faculty team could work collaboratively to continue building the site based on self-reflection of the problems and their needs, integrate the site's practical information and support into their teaching, and collect data on the impact of the intervention. For instance, the site has an authentic assessment examples database, which has the potential to grow indefinitely with contributions from instructors who have brought real world activities into their classrooms. Such an endeavour would help ensure the site's relevance and sustainability. Data could be in the form of indirect measures, such as surveys and interviews with stakeholders (namely students, other instructors, co- op employers, etc.), or direct measures of student performance (for example, assignments and exams).

\section{CONCLUSION}

Canada was one of the original signatories of the Washington Accord in 1989, yet resistance to OBE persists within faculties of Engineering nationwide [15]. Concerns encompass its potential negative impacts on teaching and learning, such as increased instructor workload, loss of academic freedom (and therefore reduced curricular innovation), and the efficacy of the pedagogical approach overall. While faculty acceptance and adoption of OBE in the classroom is necessary for an institution to maintain good standing with the CEAB, it is also important because OBE lays the foundation for teaching excellence, i.e. designing and delivering activities and assessments with learning outcomes in mind.

The purpose of this paper has been to showcase the online OBE Resource Hub for Engineering faculty at the University of Alberta, a site that consolidates theoretical and practical information in the form of articles, tipsheets, videos, external links, and more. Sharing the framework and process of development of this initiative may enable its consideration, replication, or adaption by equivalent faculties elsewhere. The underlying premise of the site's construction is that faculty resistance to OBE is ultimately due to lack of understanding and lack of resources, and that education and communication are key strategies toward addressing all concerns (Bresciani, 2006).

Recent survey feedback has already resulted in improvements to the site's layout and content quality and will continue to do so through ongoing consultation with users. It is anticipated that the site will continue to grow and refine, even after the draft version is launched and accessible by all Engineering faculty. The initiative, instead of being built for instructors, is seen to be well suited to development by instructors as they create a community of practice, and it could, perhaps, put in motion a practical action research study to gather evidence of the increased faculty buy-in and engagement with $\mathrm{OBE}$ with a resource of this nature.

\section{Acknowledgements}

The development of the OBE Resource Hub has been supported by the Faculty of Engineering at the University of Alberta.

\section{References}

[1] Liliya Akhmadeeva, Maureen Hindy, and Carolyn J. Sparrey, "Overcoming obstacles to implementing an outcome-based education model: Traditional versus transformational OBE," in Proc. CEEA Canadian Engineering Education Conf., CEEA13, (Montréal, QC; 17-20June 2013), 5 pp., 2013. 
[2] Trudy W. Banta and Charles Blaich, "Closing the assessment loop," Change: The Magazine of Higher Learning, vol. 43, no. 1, pp. 22-27, 2011.

[3] Simon Barrie, Clair Hughes, and Calvin Smith, The National Graduate Attributes Project: Integration and Assessment of Graduate Attributes in Curriculum. Strawberry Hills, NSW: Australian Learning \& Teaching Council, 2009, 51 pp. Available as of January 18, 2020, from http://hdl.voced.edu.au/10707/327383

[4] Charles Blaich and Kathleen Wise, From Gathering to Using Assessment Results: Lessons from the Wabash National Study. Champaign, IL: National Institute for Learning Outcomes Assessment (NILOA), January 2011, 20 pp. Available as of January 18, 2020, from https://www.learningoutcomeassessment.org/documen ts/Wabash 001.pdf

[5] Marilee J. Bresciani, Outcomes-Based Academic and Co-curricular Program Review: A Compilation of Institutional Good Practices. Sterling, VA: Stylus, 2006, 240 pp. \{ISBN: 978-1579221416\}

[6] Canadian Engineering Accreditation Board (CEAB), 2017 Accreditation Criteria and Procedures. Ottawa, ON: Engineers Canada, 2017, 123 pp. Available as of January 3, 2019, from https://engineerscanada.ca/sites/default/files/accreditat ion-criteria-procedures-2017.pdf

[7] Canadian Engineering Education Association (CEEA), Proceedings of the Canadian Engineering Education Association (CEEA). Winnipeg, MB: n.d. Available as of January 3, 2019, from https://ojs.library.queensu.ca/index.php/PCEEA/index

[8] John Clanchy and Brigid Ballard, "Generic skills in the context of higher education," Higher Education Research and Development, vol. 14, no. 2, pp. 155-166, 1995. Available as of January 18, 2020, from https://doi.org/10.1080/0729436950140202

[9] John W. Creswell, Educational Research: Planning, Conducting, and Evaluating Quantitative and Qualitative Research. Upper Saddle River, NJ: Pearson Education, Inc., 2015 (5th ed.), 645 pp. \{ISBN: 9780133549584\}

[10] Brian Frank, Susan McCahan, K. Christopher Watts, Susan Fostaty-Young, Peter Ostafichuck, Peter Wolf, and Nasser Saleh, "Engineering graduate attribute development (EGAD) project," in Proc. CEEA
Canadian Engineering Education Conf., CEEA11, (St. John's, NL; 6-8June 2011), 3 pp., 2011.

[11] Roy Killen, "Outcomes-based education: Principles and possibilities," Unpublished manuscript, University of Newcastle, Faculty of Education. Available as of January 18, 2020, from https://www.semanticscholar.org/paper/1OUTCOMES-BASED-EDUCATION-\%3APRINCIPLES-ANDKillen/a65eff7985df96b13398f9d9a9814a6fad3298a7

[12] George D. Kuh, Stanley O. Ikenberry, Natasha A. Jankowski, Timothy Reese Cain, Peter T. Ewell, Pat Hutchings, and Jillian Kinzie, "Making assessment matter," in Using Evidence of Student Learning to Improve Higher Education. San Francisco, CA: JosseyBass, pp. 220-236, 2015.

[13] Andres Winston C. Oreta, "Engineering educators must evolve too!," Journal of Professional Issues in Engineering Education and Practice, vol. 142, no. 1, 3 pp., 2016.

[14] Stuart Palmer, "Authenticity in assessment: Reflecting undergraduate study and professional practice," European Journal of Engineering Education, vol. 29, no. 2, pp. 193-202, 2004.

[15] Anita M. Parker, Ellen Watson, Marcus Ivey, and Jason P. Carey, "Approaches to graduate attributes and continual improvement processes in faculties of engineering across Canada: A narrative review of the literature," in Proc. CEEA Canadian Engineering Education Conf., CEEA19, (7-9June 2019), 19 pp., 2019.

[16] Linda Suskie, Five Dimensions of Quality: A Common Sense Guide to Accreditation and Accountability. San Francisco, CA: Jossey-Bass, 2015, 320 pp. \{ISBN: 978-1118761571\}

[17][16] Gabriela Lobo Viega, Edson Pinheiro de Lima, Fernando Deschamps, and Rafael Rodrigues Guimaraes Wollmann, "Performance measurement system to continuously improve a Brazilian industrial engineering program: A process to ABET accreditation," in Industrial Engineering and Operations Management II. XXIVIJCIEOM 2018, Springer Proceedings in Mathematics \& Statistics, Volume 281, J. Reis, S. Pinelas, \& N. Melano (eds.) (Springer, Cham), 2019. 